Article

\title{
Detailed Design and Aerodynamic Performance Analysis of a Radial-Inflow Turbine
}

\author{
Amir Karimi Noughabi ${ }^{1}$ and Shervin Sammak ${ }^{2, *}$ (1) \\ 1 Department of Aerospace Engineering, Amirkabir University of Technology, 424 Hafez Ave, \\ Tehran 15875, Iran; amir.karimi@rwth-aachen.de \\ 2 Center for Research Computing, University of Pittsburgh, 4420 Bayard St, Pittsburgh, PA 15213, USA \\ * Correspondence: shervin.sammak@pitt.edu; Tel.: +1-412-624-5026
}

Received: 16 October 2018; Accepted: 16 October 2018; Published: 9 November 2018

\begin{abstract}
Radial-inflow turbines (RI turbines) are critical components of air cycle machines (ACM), utilized in environment conditioning systems (ECS). In this work, a process is presented for the full design of a radial-inflow turbine, including volute, nozzle blade row and rotor blade row. The preliminary and detailed aerodynamic design approaches are explained in detail. A mean-line (1D) analysis method coupled with the preliminary design is employed to evaluate the aerodynamic performance of the RI turbine. Then, ANSYS CFX is used to perform unsteady 3D simulations of the designed RI turbine at design and off-design conditions to predict the aerodynamic performance of the turbine for future optimization.
\end{abstract}

Keywords: radial-inflow turbine; preliminary aerodynamic design; detailed aerodynamic design; mean-line analysis and 3D CFD simulation

\section{Introduction}

Compact air cycle machines (ACM) have been widely employed in many industrial applications, such as environment conditioning systems (ECS) and air cycle refrigeration. The coefficient of performance (COP) of the cooling cycles changes dramatically by efficiency and pressure ratio of the ACM [1,2]. The radial-inflow (RI) turbine is an indispensable member of the ACM, which is regularly used in compact air cooling systems because of its reliability, simplicity and robust construction, fast response, various working fluids (such as organic working fluids), low emission and low manufacturing cost [3-5]. Thus, the performance of the RI turbine is essential for these types of systems.

The aerodynamic design of the radial-inflow turbines is efficiently accomplished in well-known steps. First, a preliminary design is performed to calculate the basic stage component dimensions. An effective preliminary design provides important advantages in terms of quality and productivity for RI turbines and costs about $50 \%$ of the engineering time in the design process of a radial-inflow turbine [6]. Aungier [7] explains that the second step in the design of radial inflow turbine is the detailed design of the rotor and nozzle blades, according to the geometry dimensions obtained by the preliminary design (first step). In this step, the nozzle blade profile and the pressure and suction sides of the rotor blades are accurately determined. These detailed geometries can be ready for manufacturing. Rohlik [8] and Glassman [9] presented an analytical method to compute the geometrical dimensions of an RI turbine for maximum efficiency based on specific velocity. Rohlik considered boundary layer loss (profile loss) in nozzle and rotor and tip clearance loss in the design process. He studied the variations in turbine efficiency related to the rotor tip-radius ratio, the exit flow angle at nozzle and the ratio of nozzle blade height to rotor-inlet diameter. Glassman [9] provided a computer program to design RI turbines based on power, mass flow rate, inlet temperature and pressure. The design variables included a stator-exit angle, rotor-exit-tip to rotor-inlet radius ratio, rotor-exit-hub to tip 
radius ratio and distribution of rotor-exit tangential velocity. The program was able to compute the basic dimensions of the turbine stage, temperature and pressure at inlet and outlet sections of each component. Rodgers [10] developed an advanced program to design a small, cooled radial turbine, which operated at high inlet turbine temperature. This program was able to determine the rotor blade camber line in addition to the capabilities of the program developed by Glassman. Whitfield [11] presented a non-dimensional approach based on non-dimensional power to minimize Mach number at the rotor inlet and outlet so that the passage losses are reduced. The non-dimensional turbine design can then be transformed to the dimensional design by applying inlet stagnation conditions (total temperature and pressure) and mass flow rate. Ventura et al. [12] also provided an automated mean-line (1D) approach to the preliminary design of RI turbines. Authors used a brute-force search algorithm to select dimensions based on non-dimensional performance and geometry characteristics. Ebaid et al. [13] employed an optimization algorithm during preliminary design to remove selective open parameters such as rotor axial length. They also presented a detailed approach for nozzleless volute design. However, all aforementioned works did not describe an approach to achieve the second step in radial-inflow design. Although commercial software such as ANSYS-Vista RTD and RITAL do not provide any information about the rotor detailed design, stator geometry, stator profile and volute dimensional specifications, designers usually use them for the preliminary design $[7,14,15]$. In other similar works with preliminary design of the RI turbine, we cannot find a detailed design approach for all components of a typical RI turbine (Volute, stator and rotor) [16-20].

In this study, we redesign the radial-inflow turbine applied in the air cycle machines at Amikabir University of Technology to achieve higher efficiency such that the coefficient of performance of ACM is improved. To achieve this goal, first, a preliminary design approach has been developed based on the various available methods. Second, a method is applied to the detailed aerodynamic design of the turbine rotor blades based on Aungier [7] and then the detailed design of volute is established. After finalizing the turbine geometry, unsteady 3D simulations using ANSYS CFX are performed to compute the aerodynamic performances of the turbine, including the mass flow rate map, efficiency map, temperature drop and streamlines through the rotor and nozzle.

\section{Design Process}

The design process will be accomplished based on the predefined parameters such as total inlet temperature, total inlet pressure, mass flow rate, total-to-static pressure ratio, and specific speed (or number of rotor revolution). Equation (1) provides a relation between specific speed and rotor rotational speed. In this equation, $Q_{5}$ is the volume flow rate at rotor exit and $\Delta H_{i d}$ is the isentropic expansion from the stage inlet total conditions to rotor exit static conditions. The value of these parameters for the RI turbine installed on the ACM at the moment are presented at Table 1.

$$
n_{s}=\frac{\omega \sqrt{Q_{5}}}{\left(\Delta H_{i d}\right)^{0.75}}
$$

Table 1. Input parameters to design the RI turbine for the ACM.

\begin{tabular}{ccc}
\hline Parameter & Unit & Value \\
\hline Total inlet temperature & $\mathrm{K}$ & 364 \\
Total inlet pressure & $\mathrm{kPa}$ & 541.822 \\
mass flow rate & $\mathrm{Kg} / \mathrm{sec}$ & 0.217 \\
total-to-static pressure ratio & - & 4.85 \\
number of rotor revolution & - & 75,000 \\
\hline
\end{tabular}


Aungier [7] provided the relations presented in Equations (2) and (3) to compute other basic design parameters such as total-to-static velocity ratio, $v_{t s}$, and total-to-static efficiency, $\eta_{t s}$. The present program is able to take both of these parameters from the designer and compute them by Equations (2) and (3).

$$
\begin{gathered}
v_{t s}=0.737 n_{s}^{0.2} \\
\eta_{t s}=0.87-1.07\left(n_{s}-0.55\right)^{2}-0.5\left(n_{s}-0.55\right)^{3}
\end{gathered}
$$

As a general rule, the preferred range of values for the specific speed is 0.45 to 0.75 . However, the other design constraints such as Mach number, speed, mechanical integrity and size can impose the specific speed. In this work, the specific speed was determined by rotational speed due to mechanical integrity and sizing adaptation between the designed turbine and the previous turbine.

Figure 1 illustrates the flowchart of the design process. In preliminary design, a mean-line analysis method is used to compute the performance of the turbine designed by the preliminary design code based on the input value. In an iterating process, the final dimensions of the RI turbine are defined to achieve the design input parameters. The turbine rotor is finalized in the preliminary design method, and then exported into the detailed design code. In this step, the distribution of the blade thickness and angle at camber surface are computed and the suction and pressure surfaces of rotor blades are generated to be employed in a more accurate turbine analysis, such as quasi-3D method and CFD. In the final step of the design process, ANSYS-CFX software is applied to simulate flow in the designed turbine. This workflow enables the opportunity to modify the turbine model and therefore improve turbine performance.

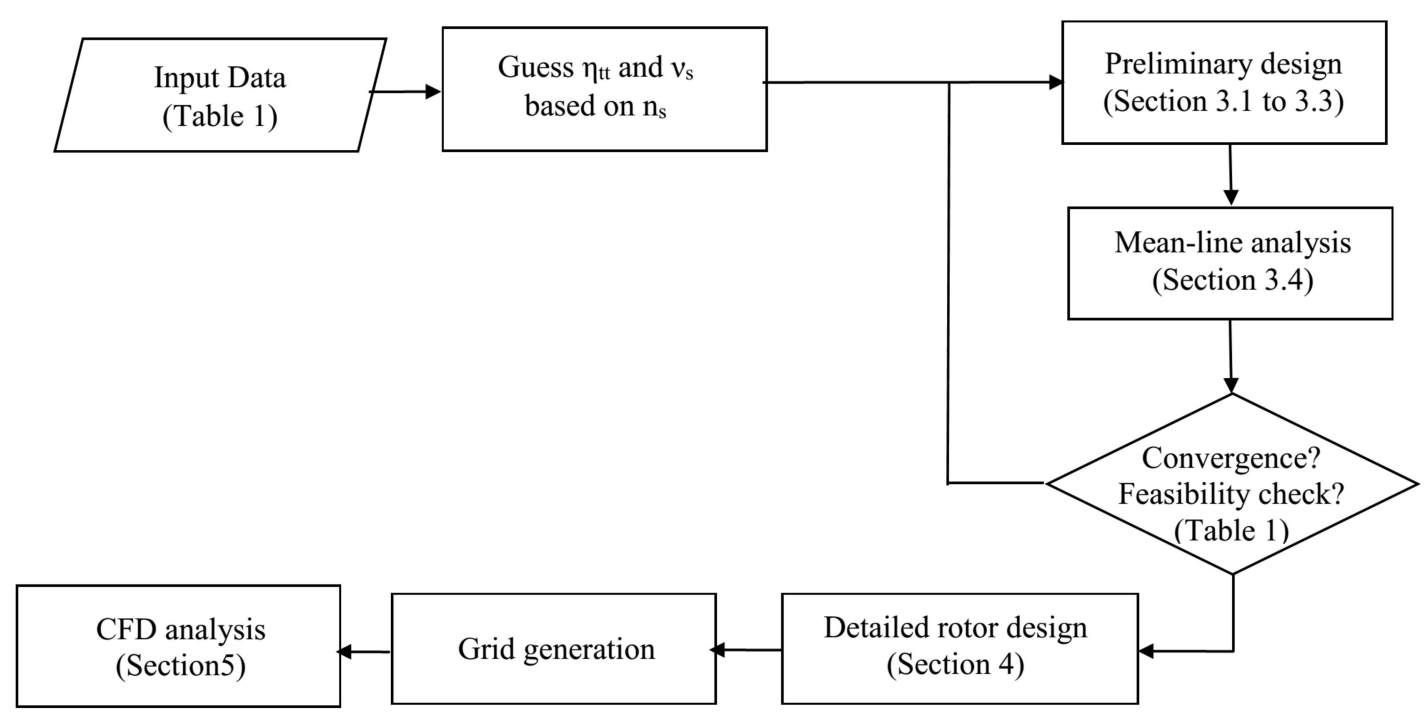

Figure 1. Design process flowchart.

\section{Preliminary Design}

The preliminary design procedure addresses the basic stage components defining the inlet volute, nozzle row, and rotor. A vaneless passage is automatically considered before and after nozzle row. The geometric and aerodynamic parameters are computed in the inlet and exit of all components shown with subscripts 1 to 5 following the station illustrated in Figure 2. 


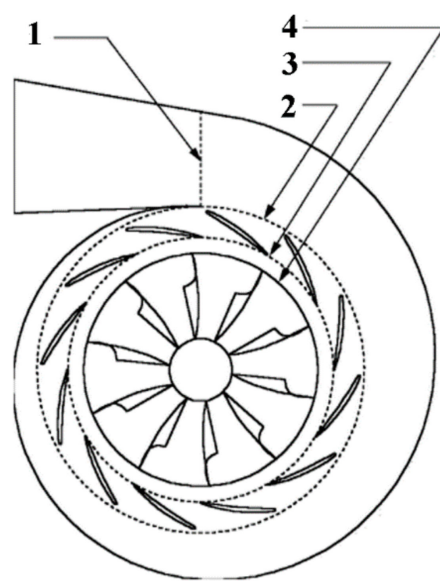

1. Volute Inlet 2. Stator Inlet 3. Stator Exit

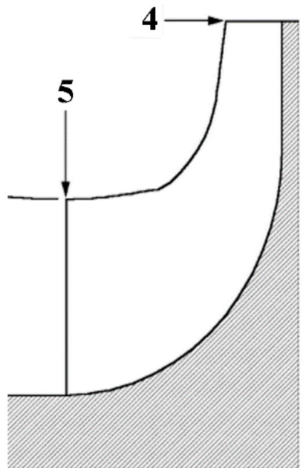
5. Rotor Exit

Figure 2. Design station for calculating geometric and aerodynamic parameters.

\subsection{Rotor Preliminary Design}

The velocity diagram is illustrated in Figure 3. In this figure, " $C$ " and " $W$ " are absolute and relative velocity, respectively. The blade and flow angle are computed related to the tangential direction.

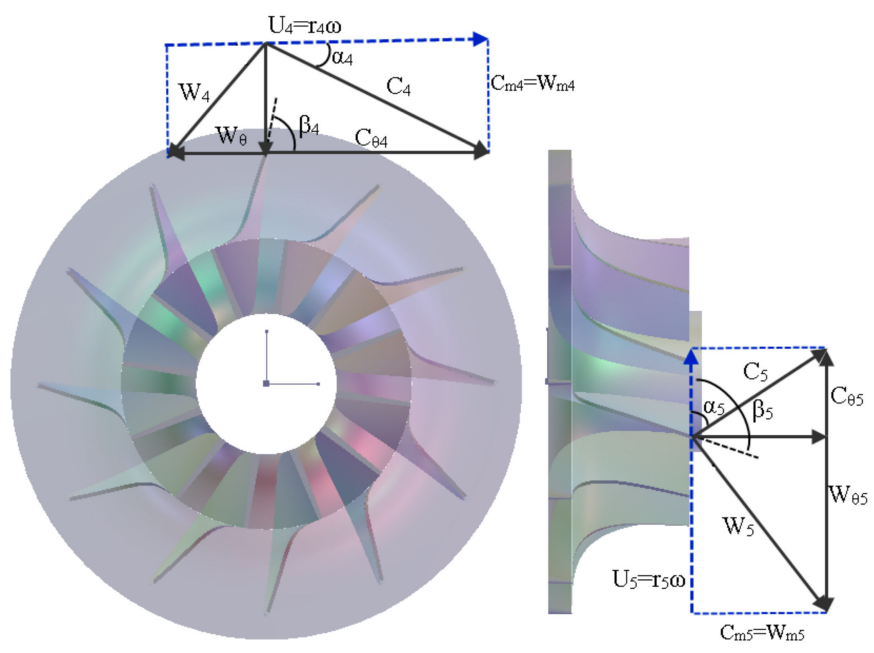

Figure 3. Velocity diagram in a rotor blade.

In rotor design, it is assumed that the inlet blade angle is constrained to be $90^{\circ}$. Since the turbine is designed for optimum performance, the exit absolute tangential velocity is considered to be zero. On the other hand, it is a reasonable assumption that the absolute Mach number at rotor exit has a relative low value in a well-designed turbine. By these assumptions, the rotor tip radius and rotor inlet tangential velocity can be computed by the following equations and using Equations (4)-(6).

$$
\begin{gathered}
U_{4}=v_{t s} C_{0 t s} \text { where } C_{0 t s}=\sqrt{2 \Delta H_{i d}} \\
r_{4}=U_{4} / \omega \\
C_{\theta 4}=U_{4} \eta_{t s} /\left(2 v_{t s}^{2}\right)
\end{gathered}
$$

Rohlik [4] recommended rotor inlet absolute flow angle as a function specific speed presented in Equation (7). Glassman [9] suggested Equation (8) to estimate the number of rotor blades based on Jamieson expression.

$$
\alpha_{4}=10.8+14.2 n_{s}^{2}
$$




$$
N_{R}=\frac{\pi}{30}\left(110-\alpha_{2}\right) \tan \alpha_{2}
$$

Aungier [7] provided the useful default relations to compute the hub radius, the ratio of meridional velocity at rotor exit to rotor inlet meridional velocity and the rotor axial length (Equations (9)-(11)). He also suggested the default equations to estimate the rotor blade thickness at the inlet and discharge stations. However, in this work, the rotor blade thickness was considered constant at all points of the rotor blade to simplify the final machining process. Though the hub radius, the blade thickness and the axial length are influenced by aerodynamic and mechanical considerations, it is more effective to use the default value for these parameters in the preliminary design. These parameters can be optimized according to aerodynamic and structural analysis.

$$
\begin{gathered}
r_{h 5}=0.185 r_{4} \\
C_{m 5} / C_{m 4}=1+5\left(b_{4} / r_{4}\right)^{2} \\
\Delta z_{R}=1.5\left(r_{s 5}-r_{h 5}\right)
\end{gathered}
$$

A well-designed rotor should satisfy a rotor exit relative Mach number less than unity. By this criteria, the mean blade pitch at the rotor exit and the rotor mean throat width could be computed by Equations (12) and (13).

$$
\begin{gathered}
s_{5}=2 \pi r_{5} / N_{R} \\
o_{5}=s_{5} C_{m 5} / W_{5}
\end{gathered}
$$

In some other research, the hub and shroud contours were assumed to be elliptical and circular arcs, respectively $[9,12]$. However, in this work, the hub contour is considered the largest circular arc, which is compatible with the rotor dimensions to minimize passage curvature effects. Since the value of the rotor axial length was less than the value of the rotor tip ratio, a linear segment is added at the rotor inlet (Figure 4). The rotor shroud contour is defined by a power law relation to obtain reasonable passage area distribution, which is shown in Equations (14) and (15) [7].

$$
\begin{gathered}
r_{s}=r_{s 5}+\left(r_{4}-r_{s 5}\right) \xi^{n} \\
\xi=\left(z_{s}-z_{5}\right) /\left(\Delta z_{R}-b_{4}\right)
\end{gathered}
$$

The value of $n$ should be selected in the range of 2 through 9 so that the mean passage area should be average of the rotor area at inlet and exit stations. In this study, this parameter is considered to be equal to 7.

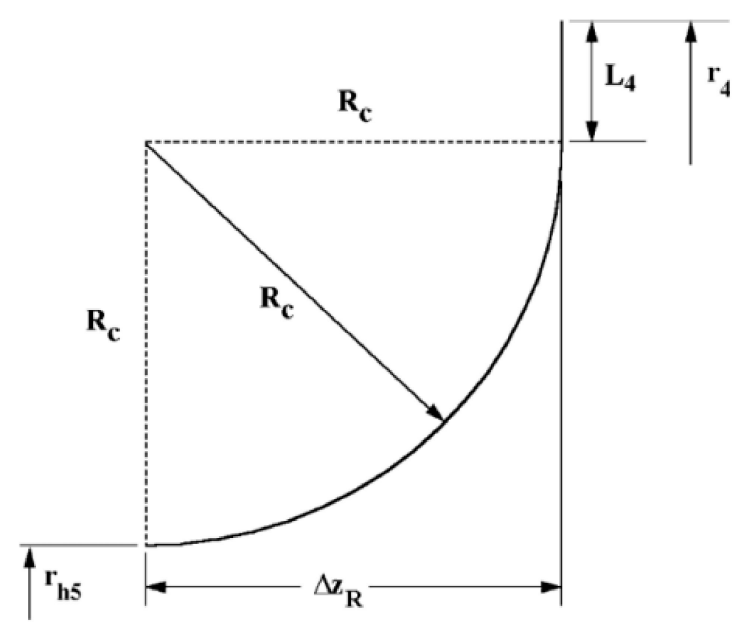

Figure 4. Rotor hub contour. 
Two different types of rotor blade usually are used in RI turbines: Straight-line element (three dimensional) and radial element blades. Straight-line element blades are constructed by connecting corresponding blade camber-line. These blades are easy to design and manufacture and usually provide more efficient blades than radial element blades. Here the rotor blades are designed based on straight-line element presented in $[7,21]$.

\subsection{Nozzle Preliminary Design}

The nozzle blade profile is usually designed and optimized according to flow velocity data [7,22]. However, it is necessary to define an initial profile for the nozzle blades. Though it is applicable to use NACA 4-digit and 5-digit airfoils to design and modify the nozzle blades in an iterative process, we have employed a general blade thickness distribution on a parabolic-arc camberline according to [23]:

$$
x^{2}+\frac{c-2 a}{b} x y+\frac{(c-2 a)^{2}}{4 b^{2}} y^{2}-c x-\frac{c^{2}-4 a c}{4 b} y=0
$$

Equation (16) includes a general parabolic-arc camberline. Since a symmetric nozzle blade will be easier to design and manufacture, Equation (16) can be simplified to a straight line $(x=0)$ by assuming $a=0.5 c$. The blade thickness distribution is adopted according to:

$$
\begin{gathered}
t=t_{r e f}+\left[t_{\text {max }}-t_{r e f}\right] \xi^{e} \\
t_{r e f}=t_{L E}+\left[t_{T E}-t_{L E}\right](x / d)
\end{gathered}
$$

where

$$
\begin{aligned}
\begin{cases}\xi=x / d & x \leq d \\
\xi=(c-x) /(c-d) & x>d\end{cases} \\
e=\sqrt{0.4 d / c}[0.95(1-x / c)(1-\xi)+0.05]
\end{aligned}
$$

Default values presented in Table 2 were considered for the constants in the Equations (17)-(20) according to Aungier [7].

Table 2. Constant parameters for the thickness distribution of the nozzle blade profile [7].

\begin{tabular}{cc}
\hline Parameter & Value \\
\hline$t_{L E} / c$ & 0.025 \\
$t_{T E} / c$ & 0.012 \\
$t_{\max } / c$ & 0.06 \\
$d / c$ & 0.4 \\
\hline
\end{tabular}

Watanabe et al. [24] recommend a minimum ratio of the nozzle exit radius to the rotor inlet radius given by Equation (21). The tangential velocity, meridional velocity and other flow data at the nozzle exit can then be computed by conservation of angular velocity, mass balance and equation of state. In addition, the nozzle passage width (blade height) is assumed to be constant.

$$
r_{3} / r_{4}=1+2 b_{4} \sin \alpha_{4} / r_{4}
$$

The nozzle throat width is defined by the sine rule for subsonic and choked flow exit according to:

$$
\begin{cases}o / s_{3}=\sin \alpha_{3} & M<1 \\ o / s_{3}=\rho_{3} C_{m 3} /\left(\rho_{*} a_{*}\right) & M=1\end{cases}
$$

To set the nozzle setting angle, $\gamma_{3}$, an iterative process will be used based on the nozzle throat width, the number of nozzle blade, and exit blade pitch to chord ratio. Simpson et al. [25] and 
Glassman [9] suggested selecting 0.75 and 0.8 for the nozzle exit blade pitch to chord ratio, respectively. The number of nozzle blade should be the lowest value, which satisfies Equation (23) [7]:

$$
\frac{4 s_{3} \sin \left(\beta_{2^{\prime}}-\alpha_{3}\right)}{c \sin \beta_{2^{\prime}}\left[1+r_{3} \sin \alpha_{3} /\left(r_{2^{\prime}} \sin \alpha_{2^{\prime}}\right)\right]} \leq 1
$$

where $\alpha_{2^{\prime}}$ and $\beta_{2^{\prime}}$ are absolute flow angle and blade angle at the nozzle inlet station, respectively.

\subsection{Volute Design}

The volute sizing depends on both the aerodynamic performances and the overall size of the stage in terms of maximum axial and radial dimensions. Since there are no dimensional restrictions for the RI turbine in the current work, an external volute was chosen to accelerate the flow to a higher discharge. The cross section of the volute is usually selected according to convenience rather than fluid dynamics principles so that the cross section shape was considered circular. Based on the design process of RI turbines presented by Aungier $[7,21]$ and Ebaid et al. [13], a vaneless passage was considered between the nozzle inlet and the volute exit stations with the inlet-to-discharge radius ratio of $1.05\left(r_{2}=1.05 r_{2^{\prime}}\right)$. The volute cross section is illustrated in Figure 5.

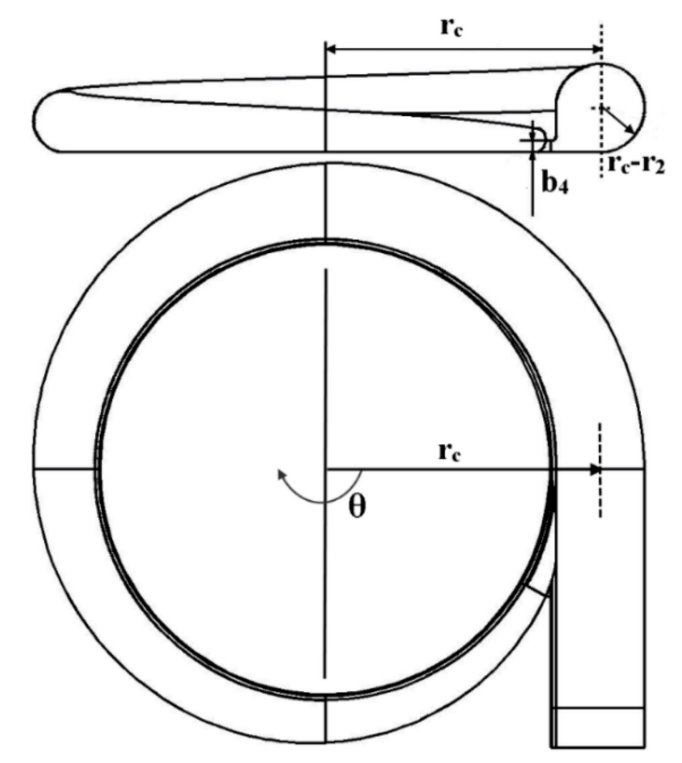

Figure 5. An external circular volute section.

The $\theta$ inlet volute area $A_{1}$, and mean radius, $r_{1}$, can be computed by applying the conservation of angular velocity $\left(r_{1} C_{1}=r_{2} C_{\theta 2}\right)$, mass balance $\left(\dot{m}=\rho_{1} C_{1} A_{1}\right)$ and thermodynamic equations in an iterative process. The area and mean radius at the other azimuth angle, $\theta$, (Figure 5 ) are defined by:

$$
A_{\theta}=\left(\frac{3}{4} \pi+1\right)\left(r_{\theta}-r_{2}\right)^{2}=\left(\frac{\rho_{2}}{\rho_{\theta}}\right) \theta b_{2} r_{\theta} \tan \left(\alpha_{2}\right)
$$

\subsection{Mean-Line Analysis}

A mean-line analysis was employed to estimate the RI turbine aerodynamic performance. The boundary layer loss (profile loss) is considered for all components of the RI turbine according to Equation (25). The detailed information to compute profile loss is presented in [7].

$$
Y_{P}=\frac{\Delta P_{t}}{P_{t_{e x}, i d}-P_{e x}}=\frac{2 \Theta+\Delta^{2}}{(1-\Delta)^{2}}
$$


$P_{t_{e x}, i d}$ and $P_{e x}$ are the ideal total pressure and actual static pressure at the discharge station of each turbine component. Total normalized boundary layer momentum thickness, $\Theta$, and boundary layer thickness, $\Delta$, are defined by Aungier. A summary of other losses considered for each component at mean-line analysis is shown in Table 3.

Table 3. Loss models used in the mean-line analysis.

\begin{tabular}{|c|c|}
\hline Types of Loss & Empirical Correlation \\
\hline Volute & \\
\hline Circumferential distortion loss & $Y_{\theta}=\left[r_{1} C_{1} / r_{3}-C_{\theta 3} / C_{3}\right]^{2}$ \\
\hline Nozzle & \\
\hline Incidence loss coefficient & $Y_{i n c}=\sin ^{2}\left(\alpha_{1}-\alpha^{*}\right) \frac{P_{t 1}-P_{1}}{P_{t 3}-P_{3}}$ \\
\hline Blade loading loss & $Y_{B L}=\frac{1}{24}\left[\frac{\Delta W}{\Delta L}\right]^{2}$ \\
\hline & $\left.1-k_{m} b_{2} W_{2}\right]^{2}$ \\
\hline Hub-to-shroud loading loss & $Y_{H S}=\frac{1}{24}\left[\frac{\kappa_{m} U_{3} V_{2}}{W_{3} \sin \alpha_{3}}\right]$ \\
\hline Incidence loss & $Y_{i n c}=\sin ^{2}\left(\alpha_{1}-\alpha_{1}^{*}\right) \frac{P_{t 1}^{\prime}-P_{1}}{P_{t 3}-P_{3}}$ \\
\hline Clearance loss & $Y_{C L}=\dot{m}_{C L} \Delta P /\left[\dot{m}\left(P_{t 3}^{\prime}-P_{3}\right)\right]$ \\
\hline
\end{tabular}

\subsection{Preliminary Design Outputs}

Table 4 shows the final geometric dimensions of the turbine stage computed by an iterative process between the preliminary design code and the mean-line analysis code. These parameters will then be used in rotor detailed design code to finalize the radial-inflow turbine geometry for CFD simulation. The final design dimensions for the volute are shown in Table 5 . The reference point for the azimuth angle, $\theta$, was illustrated in Figure 5.

Table 4. Output dimensions from preliminary design.

\begin{tabular}{ccc}
\hline Parameter & Unit & Value \\
\hline Volute & & \\
Volute inlet area, $A_{1}$ & $\mathrm{~mm}^{2}$ & 414.8 \\
Volute inlet radius, $r_{1}$ & $\mathrm{~mm}$ & 69.0 \\
Volute discharge radius, $r_{2}$ & $\mathrm{~mm}$ & 57.9 \\
Nozzle & & \\
Nozzle inlet radius, $r_{2^{\prime}}$ & $\mathrm{mm}$ & 55.1 \\
Nozzle discharge radius, $r_{3}$ & $\mathrm{~mm}$ & 48.8 \\
Nozzle exit throat width, $o_{3}$ & $\mathrm{~mm}$ & 3.6 \\
Nozzle passage width, $b_{2}=b_{3}$ & $\mathrm{~mm}$ & 2.9 \\
Nozzle inlet blade angle, $\beta_{2}$ & $\mathrm{deg}$. & 28.6 \\
Nozzle exit blade angle, $\beta_{3}$ & $\mathrm{deg}$. & 7.0 \\
Number of nozzle blade, $N_{N}$ & - & 20 \\
Rotor & & \\
Rotor inlet radius, $r_{4}$ & $\mathrm{~mm}$ & 40.6 \\
Rotor exit hub radius, $r_{h 5}$ & $\mathrm{~mm}$ & 7.5 \\
Rotor exit hub radius, $r_{s 5}$ & $\mathrm{~mm}$ & 21.8 \\
Rotor throat width, $o_{s 5}$ & $\mathrm{~mm}$ & 4.7 \\
Rotor inlet blade angle, $\beta_{4}$ & $\mathrm{deg}$. & 90.0 \\
Rotor exit blade angle, $\beta_{5}$ & $\mathrm{deg}$. & 45.9 \\
Rotor blade thickness, $t_{r}$ & $\mathrm{~mm}$ & 1.0 \\
Number of rotor blades, $N_{R}$ & - & 13 \\
\hline
\end{tabular}


Table 5. Design dimensions of the turbine volute.

\begin{tabular}{cccc}
\hline No. & Azimuth Angle [deg.] & Radius of Center [mm] & Radius of Section [mm] \\
\hline 1 & 0 & 57.90 & 1.00 \\
2 & 30 & 60.93 & 3.03 \\
3 & 60 & 62.23 & 4.33 \\
4 & 90 & 63.24 & 5.34 \\
5 & 120 & 64.11 & 6.21 \\
6 & 150 & 64.88 & 6.98 \\
7 & 180 & 65.58 & 7.68 \\
8 & 210 & 66.23 & 8.34 \\
9 & 240 & 66.85 & 8.95 \\
10 & 270 & 67.43 & 9.53 \\
11 & 300 & 67.98 & 10.09 \\
12 & 330 & 68.51 & 10.62 \\
13 & 360 & 69.02 & 11.13 \\
\hline
\end{tabular}

\section{Detailed Design of Rotor}

The general gaspath design system is employed in the rotor blades detailed aerodynamic design (Figure 6). The Bezier polynomial curve [26] is used to evaluate the hub and shroud curve imported by the preliminary design system. This curve is well suited to the gaspath design process to generate a smooth curve for the blade surfaces. The suction and pressure sides of the rotor blade at the hub and shroud can be computed by Equations (26)-(28). As is shown in the Figure 6 , the cross product of the tangent vector to blade camberline, $\vec{S}$, and the vector, $\vec{B}$, directed along the quasi-normal line determines the vector $\vec{T}$, which defines the local normal direction to camberline surface. By determining the hub and shroud contours at the suction and pressure sides, the intermediate surface coordinates are defined by connecting the hub and shroud surface points along the quasi-normal line.

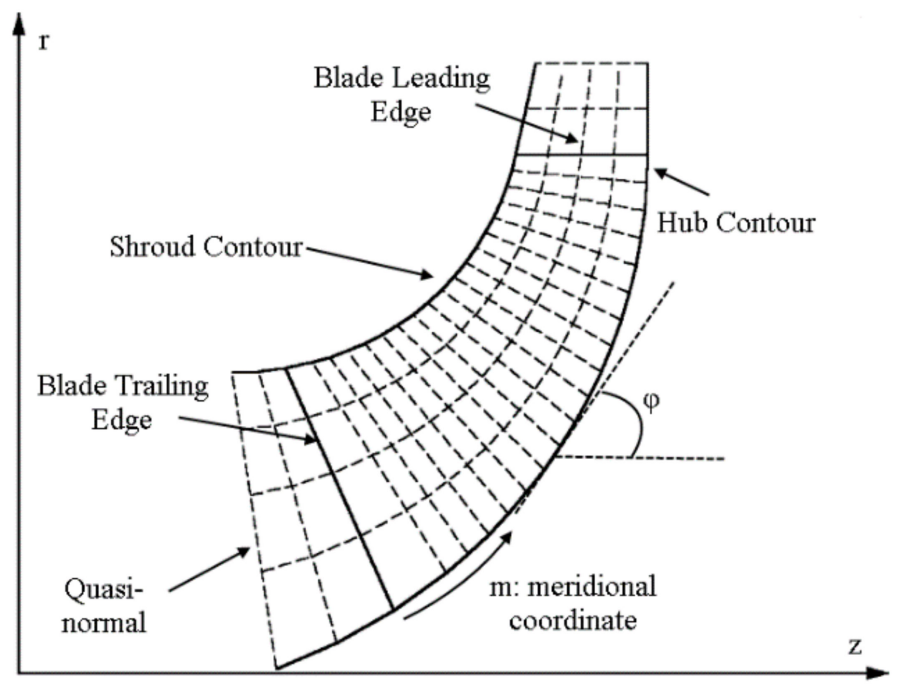

Figure 6. Gas path design system used for the rotor blade detailed design.

$$
\left[\begin{array}{c}
T_{x} \\
T_{y} \\
T_{z}
\end{array}\right]=\vec{S} \times \vec{B}=\operatorname{det}\left(\left[\begin{array}{ccc}
i & j & k \\
\sin \theta_{c} \sin \varphi \sin \beta_{c} & \cos \theta_{c} \sin \varphi \sin \beta_{c} & \cos \varphi \sin \beta_{c} \\
+\cos \theta_{c} \cos \beta_{c} & -\sin \theta_{c} \cos \beta_{c} & \\
\left(x_{c s}-x_{x h}\right) / L & \left(y_{c s}-y_{c h}\right) / L & \left(z_{c s}-z_{c h}\right) / L
\end{array}\right]\right)
$$




$$
\left\{\begin{array}{c}
x=r_{c} \sin \theta_{c} \pm \frac{1}{2} t_{r} T_{x} \\
y=r_{c} \cos \theta_{c} \pm \frac{1}{2} t_{r} T_{y} \\
z=z_{c} \pm \frac{1}{2} t_{r} T_{z} \\
\cot \beta_{c}=r_{c} \frac{d \theta_{c}}{d m}
\end{array}\right.
$$

$\theta_{c}$ and $\beta_{c}$ are blade and polar angle with respect to the tangent at the hub and shroud camberlines, respectively. The angle $\varphi$ (Figure 6) is the meridional surface slope angle with respect to $z$. It should be suitable to maintain a constant rotor tip radius for all meridional surfaces, according to Equation (29) and polar to Cartesian coordinate transformation.

$$
\left\{\begin{array}{l}
\theta_{4}=\theta_{c, 4} \pm \tan ^{-1}\left[\frac{t_{r, 4}}{2 r_{c, 4}\left(T_{x} \cos \theta_{c, 4}-T_{y} \sin \theta_{c}\right)}\right] \\
x_{4}=r_{4} \sin \theta_{4} \\
y_{4}=r_{4} \cos \theta_{4}
\end{array}\right.
$$

The final geometry of the designed radial-inflow turbine for the air cycle machine is shown in Figures 7-9, which show the rotor blade angle and the polar angle in the hub and shroud section.

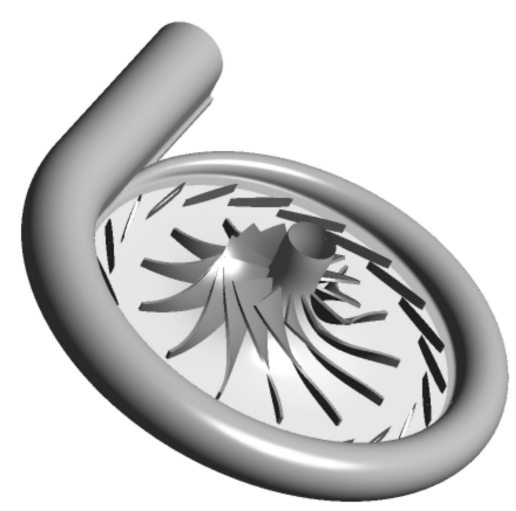

Figure 7. The final geometry of the designed RI turbine.

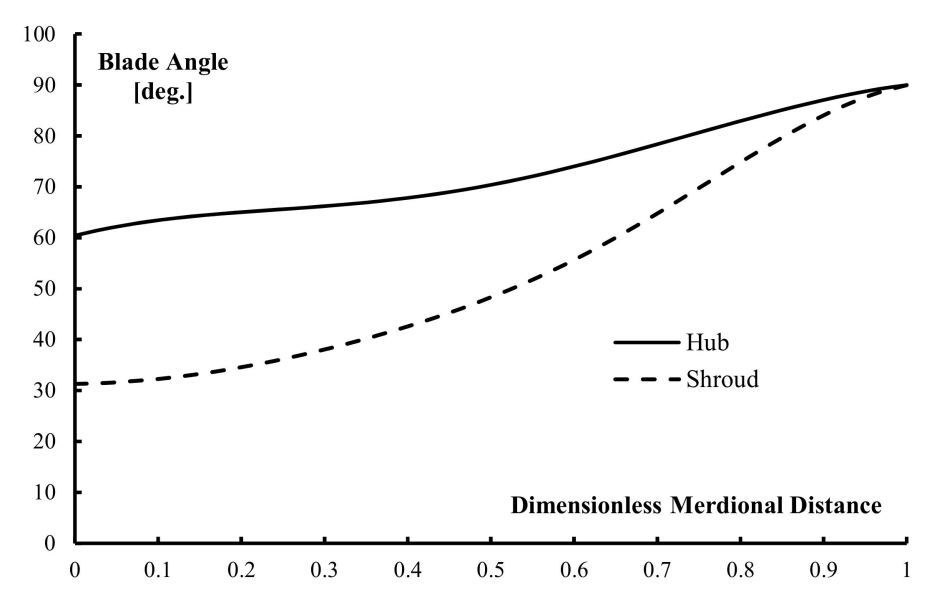

Figure 8. Rotor blade angle in the hub and shroud section. 


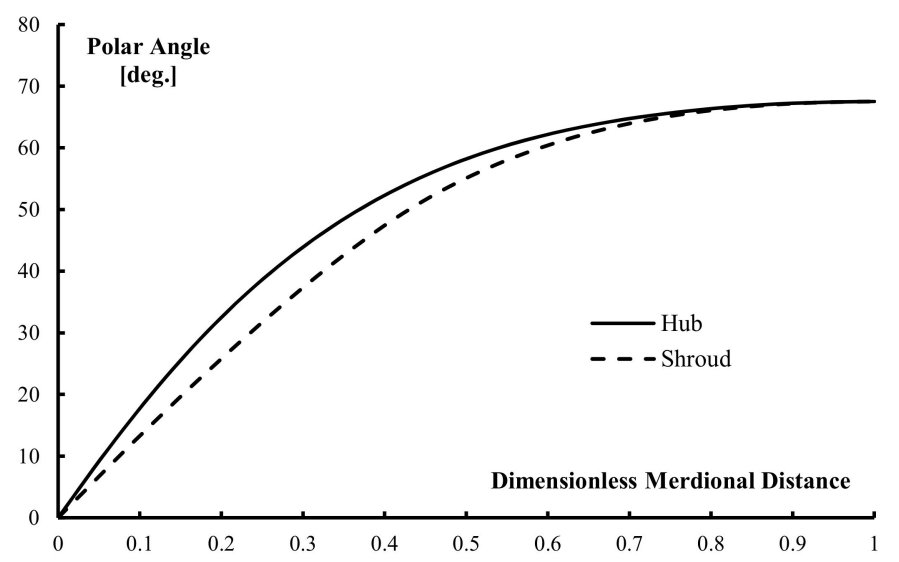

Figure 9. Rotor polar angle in the hub and shroud section.

\section{Numerical Analysis}

The CFD solver ANSYS-CFX has been used to solve the three-dimensional compressible unsteady Reynolds-averaged Navier-Stokes (URANS) equation. The high resolution discretization was employed for momentum and turbulence equations. The standard $k-\varepsilon$ has been chosen to model the turbulent flow. The pressure inlet and pressure outlet boundary conditions were set for the volute inlet and the rotor outlet. A frozen rotor interface was set between the volute and the nozzle and a mixing plane condition was set at the interface between the stationary (nozzle) and rotational (rotor) frames. Therefore, the circumferential variation of the flow has no important effects on the stage efficiency and mass flow rate. The stage interface employs time-averaging to estimate the parameters in the interface between the rotor and nozzle stages. The physical time step is considered equal to $1 / \omega$, where $\omega$ is the revolution speed in rad/sec. Due to the difference in the number of blades in the rotor and nozzle stages, a pitch angle change, which is equal to the rotor-nozzle blade ratio, is considered for the flow.

\subsection{Grid Generation}

A structured O-H three-dimensional mesh was generated by ANSYS Turbogrid software for the nozzle and rotor computational domains (Figure 10). The grid independency shown in Figure 11 was performed to choose the appropriate number of cells for the meshes of rotor and nozzle blades. The number of cells in the O-type boundary layer and spanwise direction for both nozzle and rotor has been changed from 8 to 12 and from 30 to 60, respectively. According to Figure 11, it is obvious that the suitable number of cells for the nozzle and rotor blade domain should be more than 300,000 . It was shown that the dimensionless wall distance, $y^{+}$, in the range of 30 to 200 had no obvious effects on prediction of the RI turbine aerodynamic performances so that the mesh was generated with this range of $y^{+}$in this work.
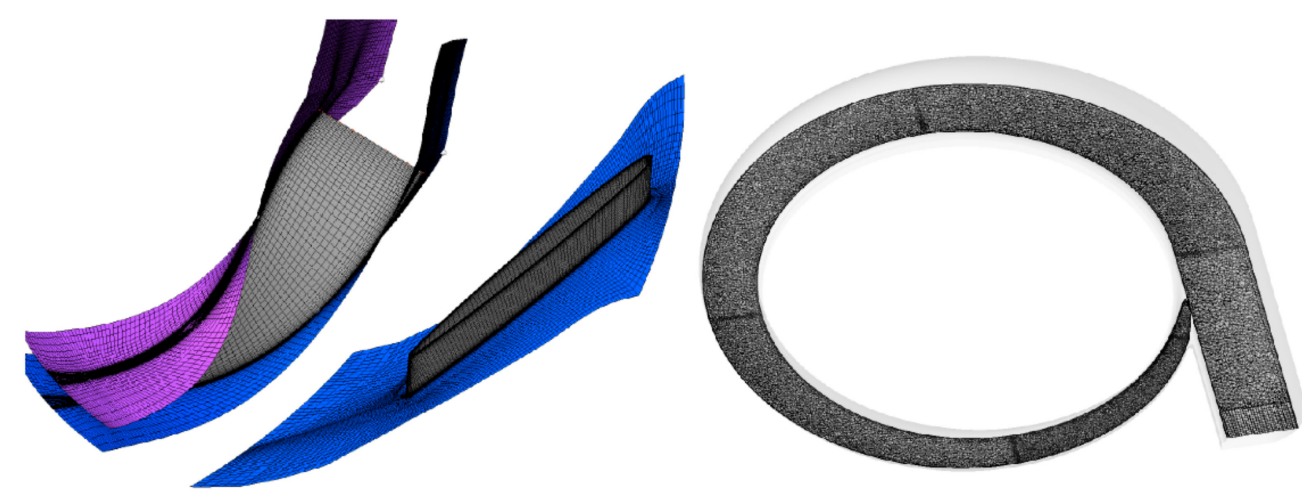

Figure 10. 3D view of the mesh generated for the newly designed turbine. 

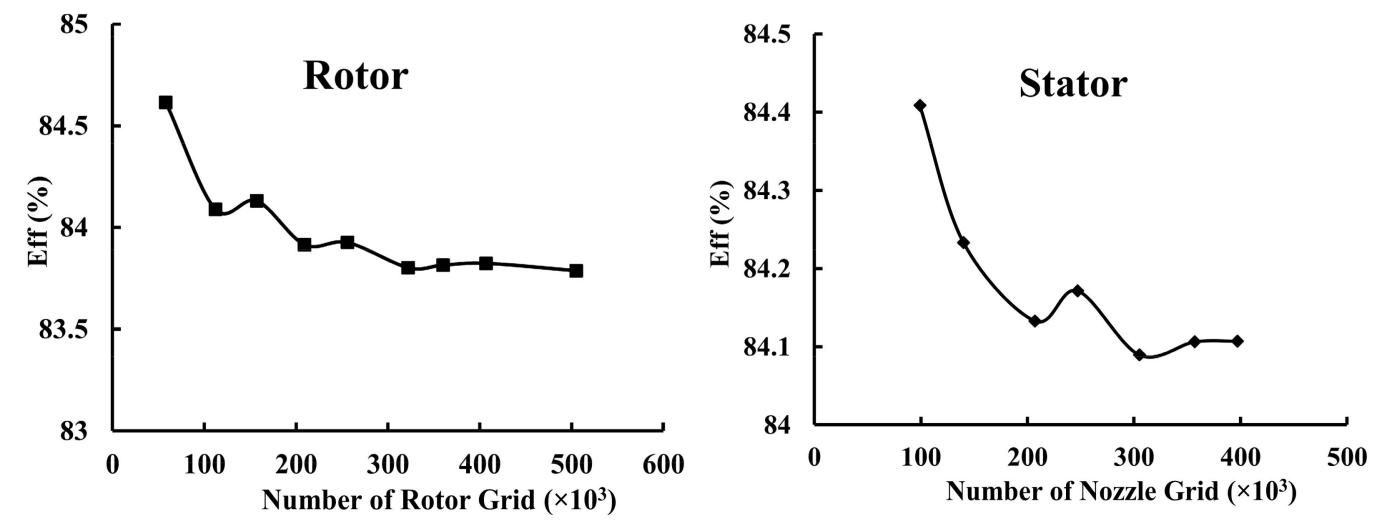

Figure 11. Grid independency for the rotor and nozzle blade rows.

\subsection{CFD Validation}

The validation of the current $3 \mathrm{D}$ viscous simulation was made against the experimental analysis of the RI turbine conducted by Hiett and Johnston [27]. Figure 12 shows a comparison of the stage performance obtained by numerical analysis and experiments. A good agreement is observed between numerical and experimental results; the deviation of stage efficiency at design point is negligible and the maximum efficiency deviation at off-design conditions is below $10 \%$.

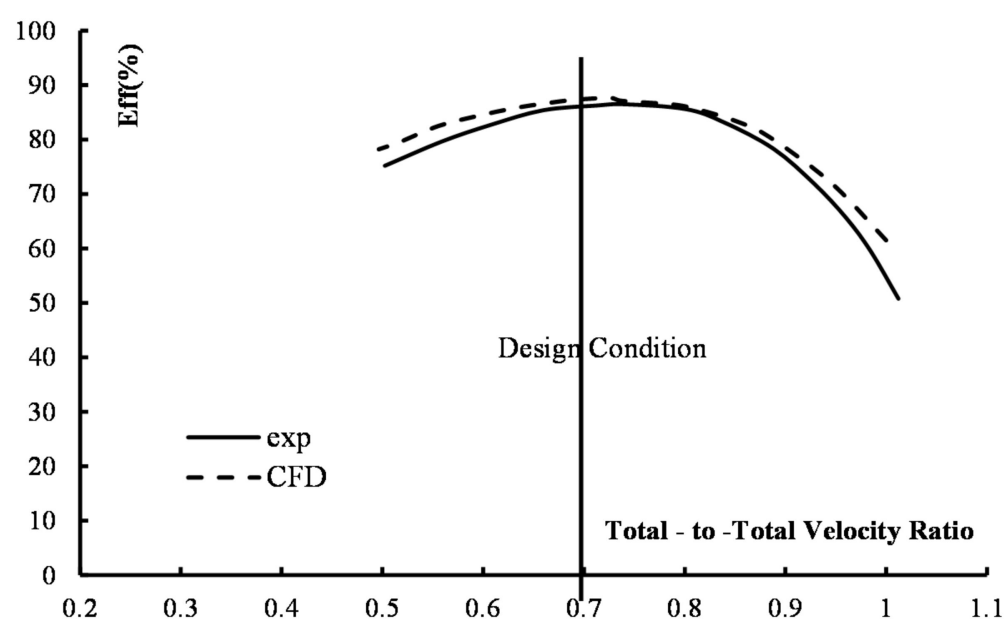

Figure 12. Comparison between experiments and CFD for the Ricardo RI turbine [27].

\subsection{CFD Results}

3D numerical simulations have been performed for design and off-design points. The mass flow rate map and the efficiency (total-to-total) map are illustrated in Figures 13 and 14. The maximum total-to-total efficiency is about $87.8 \%$ at a total-to-total velocity ratio of 0.73 . The total-total efficiency at design point is about $1.3 \%$ less than the maximum efficiency. However, the total-to-total efficiency is more than $80 \%$ for a wide range of velocity ratio $\left(0.5<v_{t t}<0.9\right)$ even at $80 \%$ of nominal speed. The corresponding points in Figures 13 and 14 show that the new design of the turbine will have a good aerodynamic performance at a low mass flow rate and off-design rotational speed. It shows that we could achieve a good design for a small radial-inflow turbine employed in an air cycle machine. In Figure 15, the total-to-total efficiency of the designed turbine was compared with that of current AUT turbine at the design speed. As illustrated in the figure, a 15\% shift in efficiency is achieved at the design conditions. 


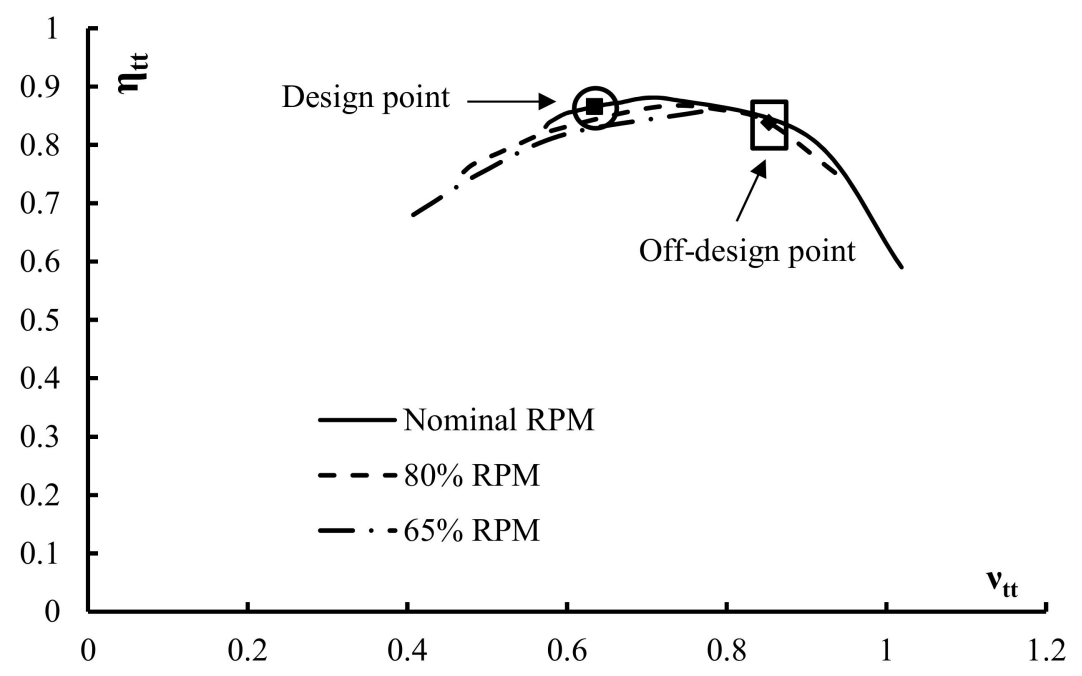

Figure 13. Total-to-total efficiency map for the new design of RI turbine.

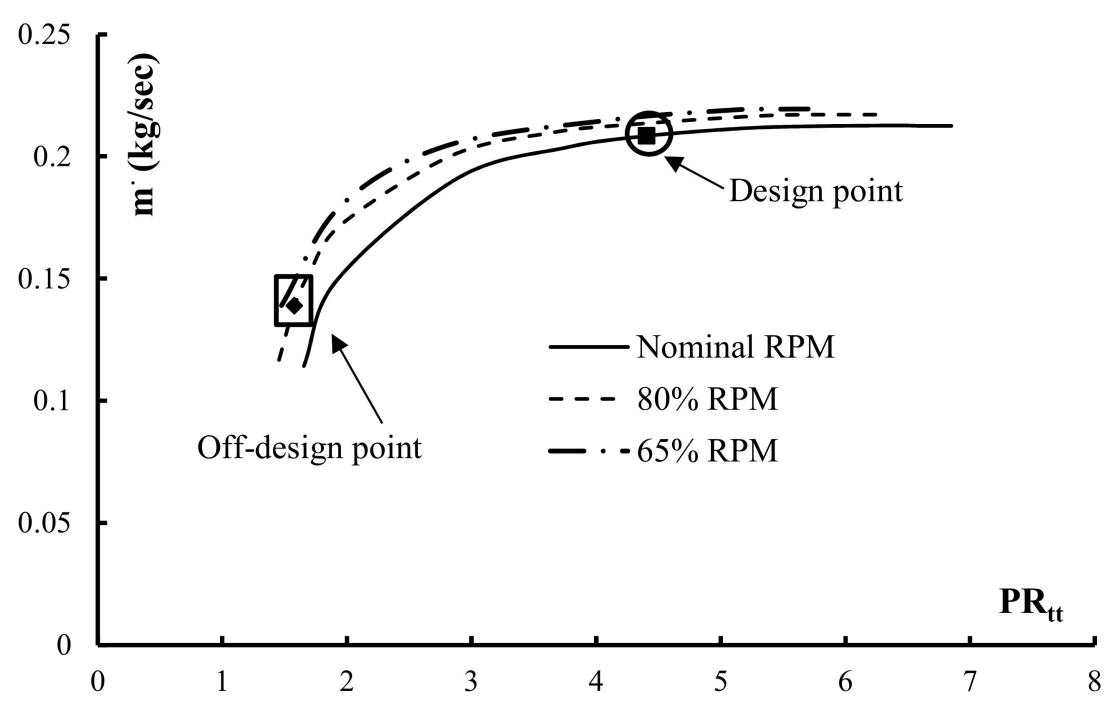

Figure 14. Mass flow rate map for the new design of RI turbine.

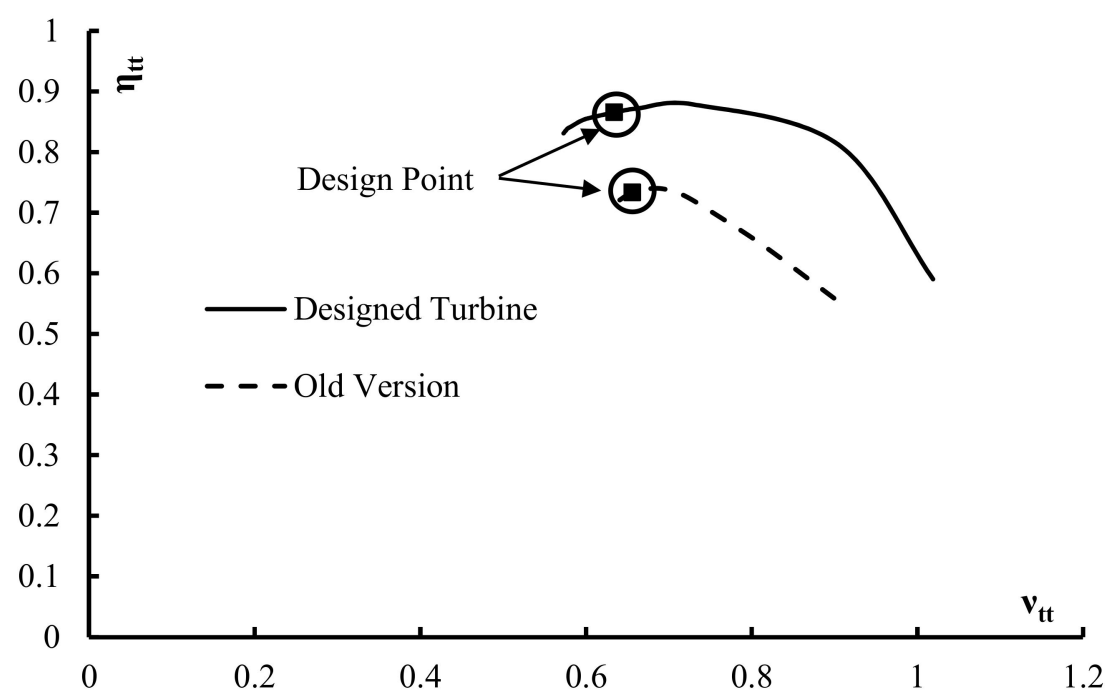

Figure 15. Comparison between the efficiency of the designed turbine and the current version. 
Figures 16 and 17 present the evolution of total-to-static temperature ratio with pressure ratio and mass flow rate at various rotational speeds. The temperature ratio is important for the turbine in an air conditioning system due to the possibility of dehumidification and icing related to temperature drops. At the design point, the static temperature drops to about $-25^{\circ} \mathrm{C}$, while the static and total pressure is slightly more than $1 \mathrm{~atm}$, making dehumidification possible. Since the low exit temperature for an RI turbine employed in air conditioning systems is unavoidable, the systems use an auxiliary passage to transfer hot air to the turbine exit. Although the possibility of the dehumidification is reduced by a reduction of mass flow rate and rotational speed, more studies and simulations with wet air are required.

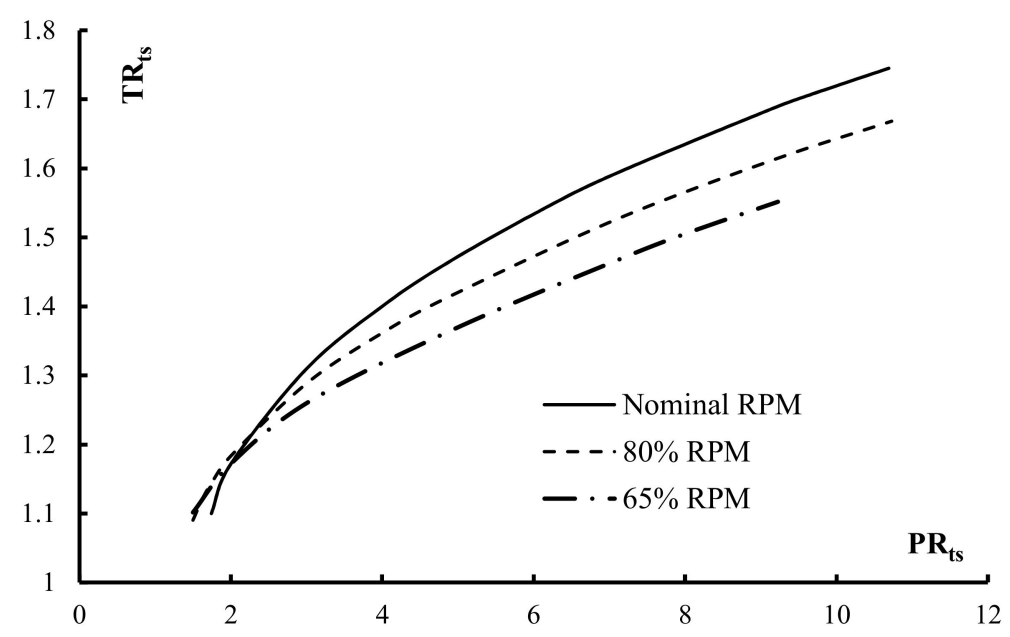

Figure 16. Evolution of total-to-static temperature with total-to-static pressure for the new design of RI turbine.

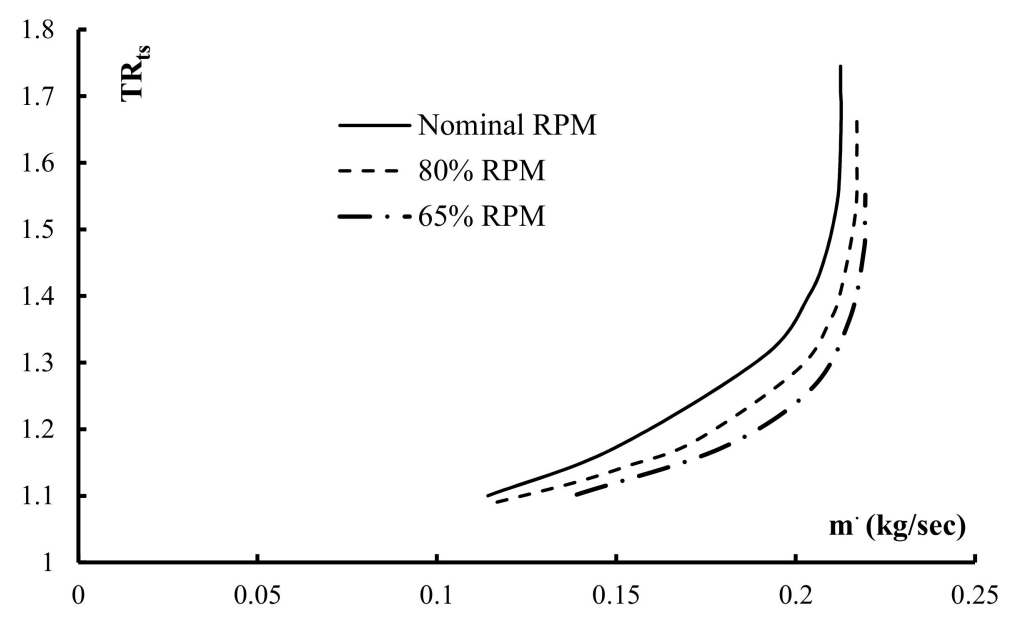

Figure 17. Evolution of total-to-static temperature with mass flow rate for the new design of RI turbine.

The meridional view of static pressure, static temperature and Mach number through stator and rotor flow passage have been presented in Figure 18. The exit station of stator has been slightly choked at design point with a maximum Mach number 1.05. The Mach and pressure contours presented in Figure 18 show that the flow expands gradually without any separation at hub. The static temperature at the exit station of the rotor change was from $273 \mathrm{~K}\left(0^{\circ} \mathrm{C}\right)$ at the shroud to $235 \mathrm{~K}\left(-38^{\circ} \mathrm{C}\right)$ at the hub. Since the mass flow rate at the design point is almost equal to the maximum mass flow rate, the range of rotor exit temperature will be more positive by the reduction in cooling demand. 


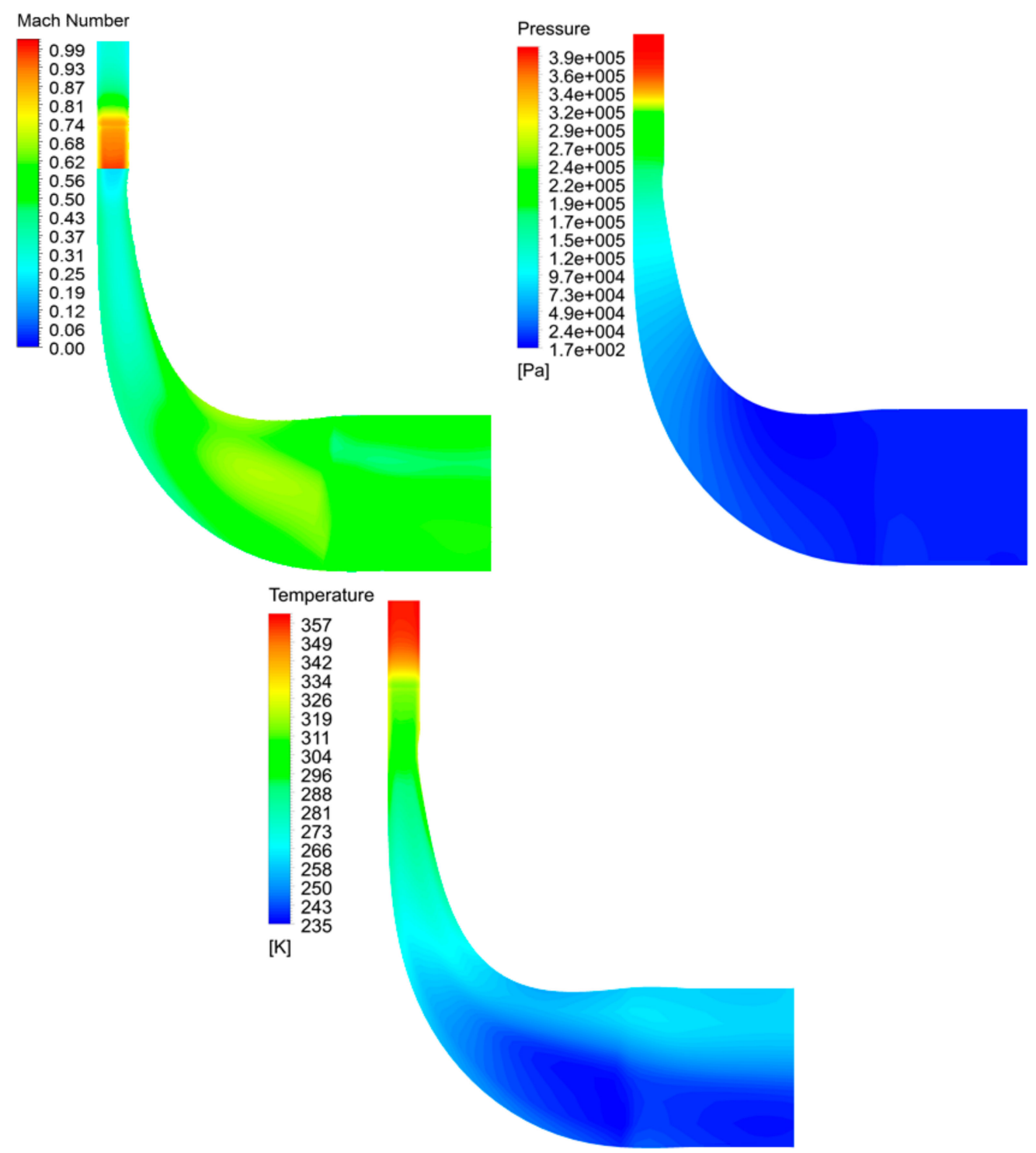

Figure 18. Meridional view of static pressure, static temperature and Mach number at the design point.

Figure 19 illustrates the streamline and Mach number contour at mid span (50\% blade height) for design point conditions. According to the figure, a small local recirculation is noticeable along the first $10 \%$ of the suction surface of the rotor blade. The recirculation bubble size increases by reduction of rotational speed and mass flow rate (at off-design conditions). In Figure 20, the streamline and Mach contour at mid-span for the $65 \%$ of nominal rotational speed and $\mathrm{PR}_{t s}=2.0$ is presented. Even at that off-design conditions, the local recirculation is only at first $20 \%$ of the suction surface. The effects of mass flow rate on the rotor leading edge recirculation are illustrated in Figure 21. As is shown in Figure 21, the recirculation is shifted from the suction surface to the pressure surface by a reduction of mass flow rate to 0.5 design value. The size of the recirculation is small enough (about $25 \%$ blade length) to have a noticeable negative effect on turbine efficiency. It shows that the new design of the RI turbine has an acceptable aerodynamic performance for a broad range of working conditions. Although circulation can be slightly improved by applying geometric modifications to the rotor blade leading edge (such as by using the elliptic leading edge), manufacturing costs will increase. 


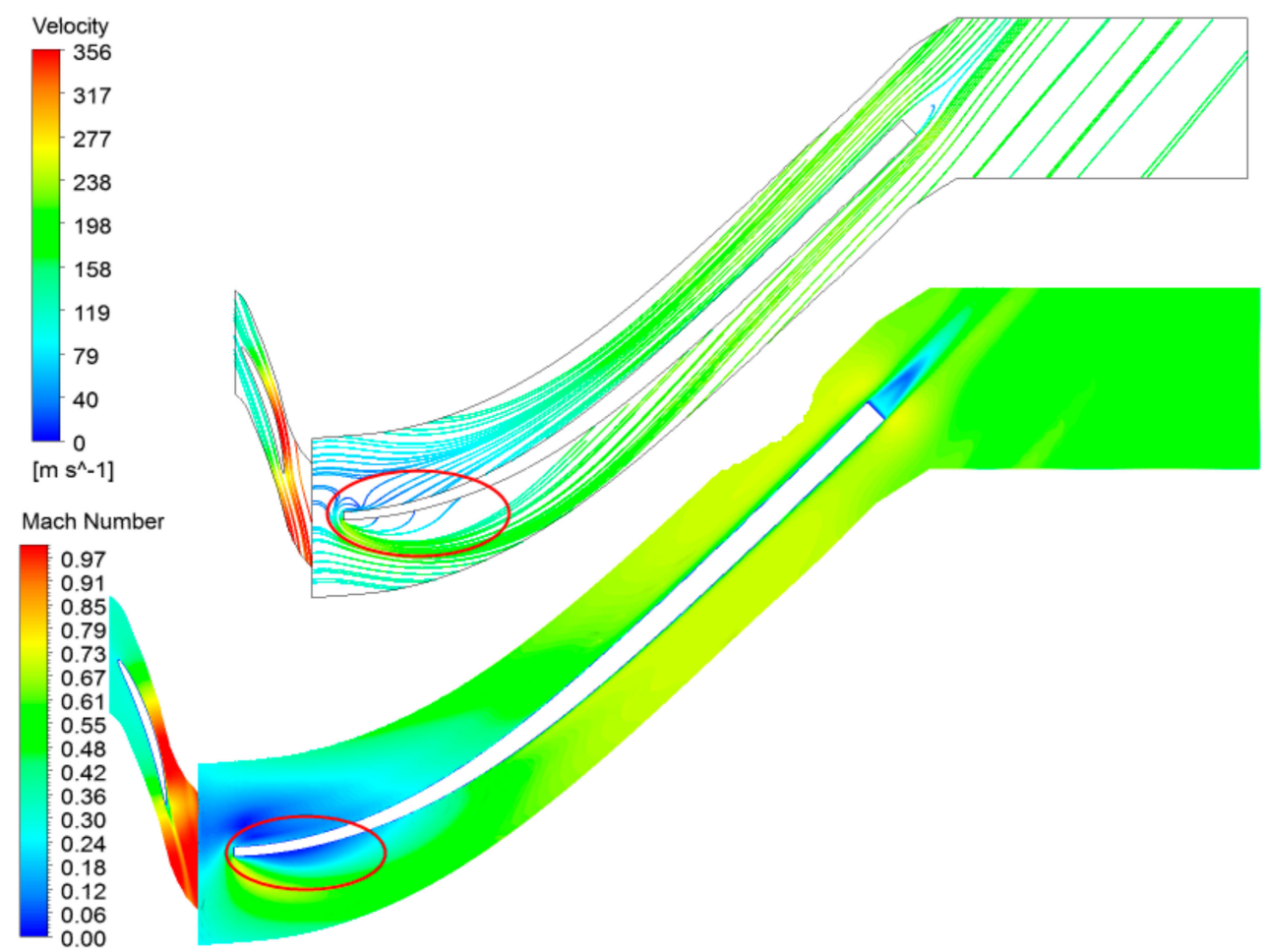

Figure 19. The streamline and Mach number contour at mid span for design point conditions.

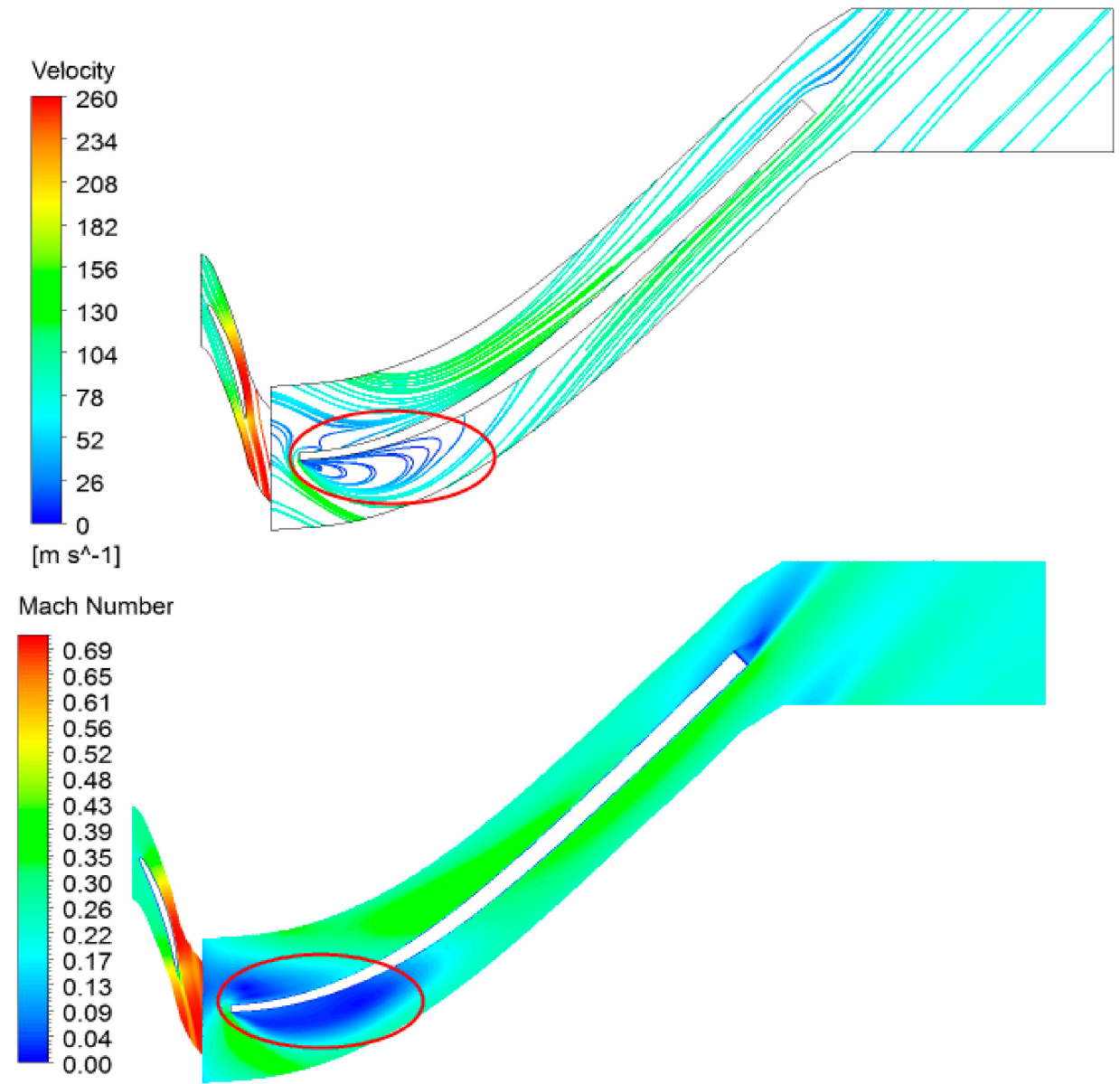

Figure 20. The streamline and Mach number contour at mid span for $65 \%$ of nominal rotational speed and $\mathrm{PR}_{t s}=2.0$. 


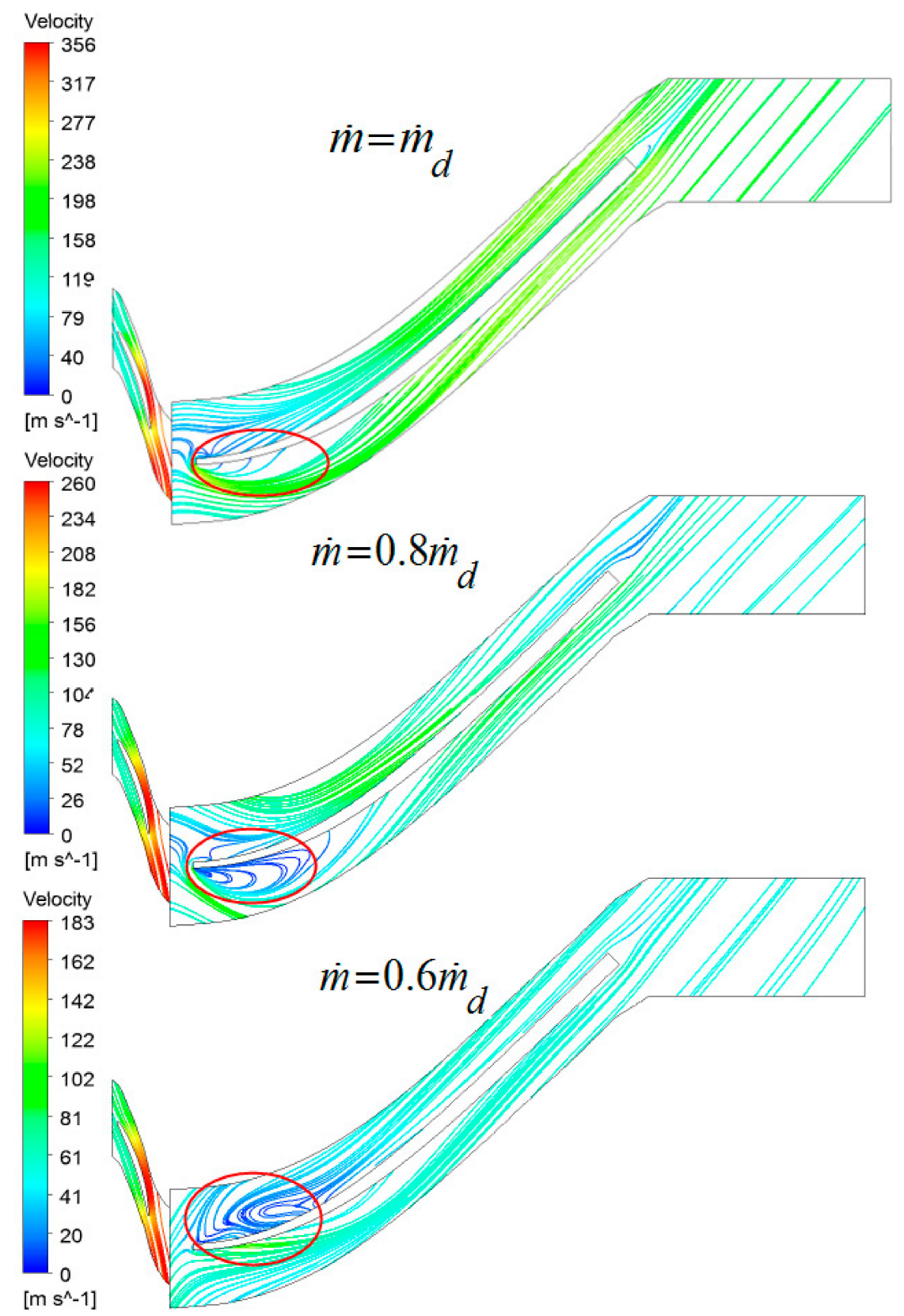

Figure 21. The streamline for different mass flow rate at mid span.

\section{Conclusions}

This paper presented a full design process for the radial-inflow turbine (RI turbine) used in an air cycle machine (ACM). The design process included a preliminary and detailed aerodynamic design for the volute, nozzle blade row, and rotor blade row. The preliminary design was coupled with a mean-line (1D) analysis to evaluate aerodynamic performance. An iteration process between the preliminary design and mean-line analysis was employed to aerodynamically achieve a high-quality turbine to be imported in the detailed design process. In detailed design, the suction and pressure surfaces of the rotor and the section surfaces of the volute were determined.

Unsteady 3D simulation using ANSYS CFX was performed to obtain the aerodynamic performance of the radial-inflow turbine designed by the presented process. The total-to-total efficiency was computed to be more than $80 \%$ for a wide range of velocity ratio $\left(0.5<v_{t t}<0.9\right)$; even at $80 \%$ of the nominal speed, the maximum value was about $87.7 \%$. The averaged rotor exit temperature was calculated at about $-25^{\circ} \mathrm{C}$ at design conditions; it is possible that dehumidification and even icing 
were observed at the rotor exit. Simulations showed that there is circulation at the rotor blade leading edge, located at the first $10 \%$ of the rotor suction surface for the design conditions and enlarged by the reduction of mass flow rate and rotational speed. However, at the critical mass flow rate, $\dot{m}=0.5 \dot{m}_{d}$, the size of the recirculation is small enough (about $25 \%$ blade length) to have a noticeable negative effect on turbine efficiency. These properties, along with the efficiency map of the turbine, shows that the design process can create a high-aerodynamic performance radial-inflow turbine, which operates at a high rotational speed in the air cycle machine.

Author Contributions: A.K.N. designed, conducted the simulation, and wrote the paper. S.S. provided guidance, suggestions for the proposed framework, and wrote the paper.

Funding: This research received no external funding.

Conflicts of Interest: The authors declare no conflicts of interest.

\section{Nomenclature}

\begin{tabular}{ll}
$A$ & Area $\left(m^{2}\right)$ \\
$a$ & Sound speed, the location of maximum camber along the chord \\
$b$ & Blade width passage $(\mathrm{mm})$, maximum camber \\
$C$ & Absolute Velocity $(\mathrm{m} / \mathrm{sec})$ \\
$C_{0}$ & Spouting Velocity $(\mathrm{m} / \mathrm{sec})$ \\
$C_{p}, C_{v}$ & Specific heats at constant pressure and volume $(\mathrm{J} / \mathrm{kg} \cdot \mathrm{K}))$ \\
$c$ & Nozzle chord \\
$d$ & Location of maximum thickness along the chord \\
$D$ & Diameter (mm) \\
$H$ & Total enthalpy $(\mathrm{J} / \mathrm{kg})$ \\
$\dot{m}$ & Mass flow rate $(\mathrm{kg} / \mathrm{sec})$ \\
$N$ & Number of rotor $/$ nozzle and splitter blades \\
$n_{S}$ & Specific Speed \\
$Q$ & Volume flow rate \\
$o$ & Throat width (mm) \\
$P$ & Pressure (Pa) \\
$P R$ & Pressure Ratio \\
$r$ & Radius (mm) \\
Re & Reynolds number \\
$s$ & Blade pitch (mm) \\
$T$ & Temperature $(\mathrm{K})$ \\
$T R$ & Temperature ratio \\
$t$ & Blade thickness (mm) \\
$U$ & Blade local velocity (m/sec) \\
$W$ & Relative Velocity (m/sec) \\
$x$ & X-coordinate of nozzle airfoil \\
$Y$ & Loss coefficient \\
$y$ & Y-coordinate of nozzle airfoil \\
$Z$ & Axial dimension \\
Greek Symbols & \\
$\alpha$ & Absolute flow angle (deg.) \\
$\beta$ & Blade angle (deg.) \\
$\gamma$ & Specific heat ratio \\
$\Delta$ & Total dimensionless boundary layer displacement thickness \\
$\eta$ & Efficiency \\
$\Theta$ & Total dimensionless boundary layer momentum thickness \\
$\theta$ & Boundary layer momentum thickness (mm), polar angle $(\mathrm{deg})$. \\
& \\
\hline &
\end{tabular}




$\begin{array}{ll}v & \text { Velocity ratio } \\ \rho & \text { Density (kg/sec) } \\ \phi & \text { Mean surface angle with axial direction (deg.) } \\ \omega & \text { Angular Velocity (rad/sec) } \\ \text { Subscripts } & \\ 1,2,3,4,5 & \text { State point in the turbine } \\ \text { ave } & \text { Average of a value } \\ B L & \text { Blade loading } \\ C L & \text { Clearance } \\ H S & \text { Hub-to-shroud } \\ \text { ins } & \text { Incidence } \\ i d & \text { Isentropic } \\ h & \text { Hub } \\ m & \text { Meridional component } \\ m a x & \text { Maximum value } \\ p & \text { Profile loss } \\ R & \text { Rotor } \\ r e f & \text { Reference value } \\ s & \text { Shroud } \\ t & \text { Total condition } \\ t s & \text { Total-to-static } \\ t t & \text { Total-to-total } \\ \theta & \text { Tangential component/circumferentially } \\ * & \text { Parameter corresponding to sonic flow } \\ \text { Superscript } & \\ * & \text { Optimum }\end{array}$

\section{References}

1. Conceição, S.T.; Zaparoli, E.L.; Turcio, W.H. Thermodynamic Study of Aircraft Air Conditioning Air Cycle Machine: 3-wheel $\times$ 4-wheel. SAE Tech. Paper 2007.

2. Santos, A.P.; Andrade, C.R.; Zaparoli, E.L. A Thermodynamic Study of Air Cycle Machine for Aeronautical Applications. Int. J. Thermodyn. 2014, 17, 117-225. [CrossRef]

3. Simpson, A.T.; Spence, S.W.; Watterson, J.K. A Comparison of the Flow Structures and Losses Within Vaned and Vaneless Stators for Radial Turbines. J. Turbomach. 2009, 131, 031010. [CrossRef]

4. Rohlik, H. Analytical determination of radial inflow turbine design geometry for maximum efficiency. In National Aeronautics and Space Administration; NASA Lewis Research Center: Cleveland, OH, USA, 1969; p. 4384.

5. Feng, Z.; Deng, Q.; Li, J. Aerothermodynamic Design and Numerical Simulation of Radial Inflow Turbine Impeller for a 100kW Microturbine. Am. Soc. Mech. Eng. 2005, 1, 873-880.

6. Zheng, Y.; Hu, D.; Cao, Y.; Dai, Y. Preliminary design and off-design performance analysis of an Organic Rankine Cycle radial-inflow turbine based on mathematic method and CFD method. Appl. Therm. Eng. 2017, 112, 25-37. [CrossRef]

7. Aungier, R.H. Turbine Aerodynamics: Axial-Flow and Radial-Flow Turbine Design and Analysis; ASME: New York, NY, USA, 2006; pp. 10016-15990.

8. Rohlik, H.E. Turbine Design and Application: Radial-Inflow Turbine; NASA: Washington, DC, USA, 1975; p. 392.

9. Glassman, A.J. Computer Program for Design Analysis of Radial-Inflow Turbines; NASA-TN-D-8164; NASA: Washington, DC, USA, 1976; p. 66.

10. Rodgers, C. Advanced Radial Inflow Turbine Rotor Program: Design and Dynamic Testing; NASA-CR-135080, SOLAR-ER-2519; NASA: Washington, DC, USA, 1976.

11. Whitfield, A. The Preliminary Design of Radial Inflow Turbines. J. Turbomach. 1990, 112, 50. [CrossRef]

12. Ventura, C.A.; Jacobs, P.A.; Rowlands, A.S.; Petrie-Repar, P.; Sauret, E. Preliminary Design and Performance Estimation of Radial Inflow Turbines: An Automated Approach. J. Fluids Eng. 2012, 134, 31102. [CrossRef] 
13. Ebaid, M.S.Y.; Bhinder, F.S.; Khdairi, G.H. A Unified Approach for Designing a Radial Flow Gas Turbine. J. Turbomach. 2003, 125, 598. [CrossRef]

14. Al Jubori, A.; Daabo, A.; Al-Dadah, R.K.; Mahmoud, S.; Ennil, A.B. Development of micro-scale axial and radial turbines for low-temperature heat source driven organic Rankine cycle. Energy Convers. Manag. 2016, 130, 141-155. [CrossRef]

15. Sauret, E.; Gu, Y. Three-dimensional off-design numerical analysis of an organic Rankine cycle radial-inflow turbine. Appl. Energy 2014, 135, 202-211. [CrossRef]

16. Fiaschi, D.; Innocenti, G.; Manfrida, G.; Maraschiello, F. Design of micro radial turboexpanders for ORC power cycles: From 0D to 3D. Appl. Therm. Eng. 2016, 99, 402-410. [CrossRef]

17. Li, Y.; Ren, X.D. Investigation of the organic Rankine cycle (ORC) system and the radial-inflow turbine design. Appl. Therm. Eng. 2016, 96, 547-554. [CrossRef]

18. Costall, A.W.; Hernandez, A.G.; Newton, P.J.; Martinez-Botas, R.F. Design methodology for radial turbo expanders in mobile organic Rankine cycle applications. Appl. Energy 2014, 157, 729-743. [CrossRef]

19. Rahbar, K.; Mahmoud, S.; Al-Dadah, R.K.; Moazami, N.; Mirhadizadeh, S.A. Development and experimental study of a small-scale compressed air radial inflow turbine for distributed power generation. Appl. Therm. Eng. 2017, 116, 549-583. [CrossRef]

20. Zhou, A.; Song, J.; Li, X.; Ren, X.; Gu, C. Aerodynamic design and numerical analysis of a radial inflow turbine for the supercritical carbon dioxide Brayton cycle. Appl. Therm. Eng. 2018, 132, 245-255. [CrossRef]

21. Aungier, R.H. Centrifugal Compressors: A Strategy for Aerodynamic Design and Analysis; ASME Press: New York, NY, USA, 2000.

22. Jones, A.C. Design and Test of a Small, High Pressure Ratio Radial Turbine. J. Turbomach. 1996, 118, 362. [CrossRef]

23. Aungier, R.H. Axial-Flow Compressors: A Strategy for Aerodynamic Design and Analysis; ASME Press: New York, NY, USA, 2003; pp. 10016-15990.

24. Watanabe, I.; Ariga, I.; Mashimo, T. Effect of Dimensional Parameters of Impellers on Performance Characteristics of a Radial-Inflow Turbine. J. Eng. Power 1971, 93, 81. [CrossRef]

25. Simpson, A.; Spence, S.; Watterson, J. Numerical and Experimental Study of the Performance Effects of Varying Vaneless Space and Vane Solidity in Radial Inflow Turbine Stators. In Proceedings of the ASME Turbo Expo 2008: Power for Land, Sea and Air GT2008, Berlin, Germany, 9-13 June 2008; Volume 135, pp. 1495-1505.

26. Forrest, A.R. Interactive interpolation and approximation by Bézier polynomials. Comput. Des. 1990, 22, 527-537. [CrossRef]

27. Hiett, G.F.; Johnston, I.H. Experiments Concerning the Aerodynamic Performance of Inward Flow Radial Turbines. Proc. Inst. Mech. Eng. Conf. Proc. 2006, 178, 28-42. [CrossRef] 